\title{
New approach for proximate analysis by thermogravimetry using $\mathrm{CO}_{2}$ atmosphere
}

\author{
Validation and application to different biomasses
}

\author{
Lilian D. M. Torquato ${ }^{1} \cdot$ Paula M. Crnkovic ${ }^{2} \cdot$ Clóvis A. Ribeiro $^{1} \cdot$ \\ Marisa S. Crespi ${ }^{1}$
}

Received: 29 January 2016/Accepted: 1 October 2016/Published online: 28 October 2016

(C) Akadémiai Kiadó, Budapest, Hungary 2016

\begin{abstract}
This study investigates the most appropriate conditions to perform the proximate analysis (moisture, volatile matter, fixed carbon, and ash) of biomasses by thermogravimetry, focusing on providing better distinction for quantification of volatile and fixed carbon components. It was found, using a series of thermogravimetric methodologies, that heating rate and particle size are important factors to be taken into account, whereas temperature and carrier gas (type and flow rate) are critical to enable the proper quantification of volatiles and fixed carbon. In this case, the best condition was achieved by applying $600{ }^{\circ} \mathrm{C}$ and $\mathrm{CO}_{2}$ as carrier gas (instead of $\mathrm{N}_{2}$ ). It is the highlight of the proposal method regarding the conditions often applied for this purpose. Furthermore, this method has proved to be advantageous in three important aspects: A single measurement is enough for quantification of all properties, it can be performed in a short time ( $1 \mathrm{~h} 27 \mathrm{~min})$ in comparison with methods performed in a muffle furnace, and it can be applied for different kinds of biomasses, from lignocellulosic to residues. The procedure of validation demonstrated
\end{abstract}

Electronic supplementary material The online version of this article (doi:10.1007/s10973-016-5882-z) contains supplementary material, which is available to authorized users.

Lilian D. M. Torquato

liliantorquato@yahoo.com.br

$\triangle$ Clóvis A. Ribeiro

ribeiroc@iq.unesp.br

1 Department of Analytical Chemistry, Institute of Chemistry, UNESP - São Paulo State University, Araraquara, São Paulo 14800-060, Brazil

2 Department of Mechanical Engineering, School of Engineering of São Carlos, USP - University of São Paulo, São Carlos, São Paulo 13560-590, Brazil the low uncertainty of the data obtained by this method and the low propagation of uncertainty when they were applied for the prediction of the high heating value of the related biomasses, which supports its applicability as an alternative to biomass characterization.

Keywords Biomass characterization · Proximate analysis · Thermogravimetric methodology $\cdot$ Method validation . HHV prediction

\section{Introduction}

Each biomass has its specific properties, which strongly influence the process in which they can be used. Therefore, due to technological and environmental reasons, the proper characterization of fuel is essential to apply it to thermal conversion processes, such as combustion, gasification, and pyrolysis [1].

The main chemical properties that provide information on fuel are a calorific value (low and high heating value), ultimate analysis $(\mathrm{C}, \mathrm{H}, \mathrm{N}, \mathrm{S}$, and $\mathrm{O})$, and proximate analysis (moisture, ash, volatile, and fixed carbon) [2]. In the proximate analysis, the properties evaluated provide an estimate of the feedstock efficiency in the power generation as well as the yield of fuel by-products in thermal conversion systems [3].

Several standard methodologies are used to determine the proximate analysis parameters for fossil fuels [4] and renewable fuels [1]. In all these methods, each parameter is determined separately in a vertical electric furnace. For instance, for renewable materials, the procedures described in the American Society for Testing Materials (ASTM) for moisture, volatile matter, and ash determination are described in E871 [5], E872 [6], and D1102 [7], respectively. 
Fixed carbon is only obtained by mass difference, which strongly depends on the other parameters determined previously, so the samples employed in each procedure must have the same moisture contents [8]. This requirement can represent a limitation for application of such methods.

In the case of biomass, it would be reasonable to adopt the proximate analysis methods developed for wood fuels (ASTM E872) because of their similar composition, despite their diversity. Meanwhile, these methods have previously been developed based on those for fossil fuels (ASTM D3175) [9], employing very high temperatures $\left(950^{\circ} \mathrm{C}\right)$, particularly in the case of volatiles determination. However, biomass devolatilization takes place at a lower temperature, compared to coals [10], due to the differences in their compositional structures. When such high temperatures are applied to biomass materials, the decomposition of the sample can occur before the evaluation of the fixed carbon content. Therefore, the analysis of biomass using techniques originally designed for fossil fuels could result in unreliable data.

Also, although these standard methodologies are already laid down for the performance of proximate analysis, they are time-consuming and require large amounts of samples. They also depend on the accuracy of the operator and comprise several steps, which may result in low reproducibility.

Thermogravimetry has been described as a suitable technique for proximate analysis determination for both fossil fuels [11-16] and biofuels [17, 18]. It is a valuable quantitative analytical method because it enables a continuous and fast measurement under controlled temperature conditions, employs a small sample mass, requires minimal operator intervention, and is low risk. However, to achieve these benefits is essential the prior knowledge of the composition of the sample as well as the influence of experimental conditions on its characterization by means of thermal analysis techniques.

Hence, considering the importance of proximate analysis for characterization of biomass for energy use, the goal of this work was to evaluate the most appropriate conditions for determination of moisture, volatile matter, fixed carbon, and ash contents in biomass by thermogravimetry. For this reason, this study evaluates a set of thermogravimetric methodologies, considering critical experimental parameters such as temperature, heating rate, particle size, as well as type, and flow rate of the carrier gas.

The best conditions were summarized in a thermogravimetric methodology, and the method was then validated to ensure their applicability and reproducibility to different types of biomass.

\section{Materials and methods}

\section{Biomass samples: source and preparation}

Different types of biomass samples were studied: two samples of sewage sludge from different sources and lignocellulosic agricultural residues. Their chemical properties are shown in Table 1.

The lignocellulosic samples were pine (Pinus elliottii engelm) sawdust, peanut (Arachis hypogaea) shell, coffee (Coffea arabica) husk, rice (Oryza sativa) husk, tucumã (Astrocaryum aculeatum) seed (endocarp), and sugar cane (Sacharaum officinarum) bagasse. They were obtained in different regions of Brazil. Pine sawdust, sugar cane bagasse, peanut shell, and coffee husk were obtained from industrial facilities, respectively, in the cities of Itapeva $\left(23^{\circ} 58^{\prime} 56^{\prime \prime} \mathrm{S}\right.$, $\left.48^{\circ} 52^{\prime} 32^{\prime \prime} \mathrm{W}\right)$, Ibaté $\left(21^{\circ} 57^{\prime} 17^{\prime \prime} \mathrm{S}, 47^{\circ} 59^{\prime} 48^{\prime \prime} \mathrm{W}\right)$, Botucatu $\left(22^{\circ} 53^{\prime} 09^{\prime \prime} \mathrm{S}, 48^{\circ} 26^{\prime} 42^{\prime \prime} \mathrm{W}\right)$, and Campinas $\left(22^{\circ} 54^{\prime} 21^{\prime \prime} \mathrm{S}\right.$, $47^{\circ} 3^{\prime} 39^{\prime \prime} \mathrm{W}$ ), in São Paulo State. Rice husk was obtained in State of Maranhão $\left(02^{\circ} 31^{\prime} 17^{\prime \prime} \mathrm{S}, 45^{\circ} 04^{\prime} 57^{\prime \prime} \mathrm{W}\right)$, and tucumã seed was collected from the Amazon rainforest, State of Pará.

Regarding to sludge samples, they were generated from the biological sewage treatment in urban wastewater treatment plants (UWWTP) of Araraquara $\left(21^{\circ} 47^{\prime} 41^{\prime \prime} \mathrm{S}, 48^{\circ} 10^{\prime} 34^{\prime \prime} \mathrm{W}\right)$ and São José do Rio Preto $\left(20^{\circ} 49^{\prime} 13^{\prime \prime} \mathrm{S}, 49^{\circ} 22^{\prime} 47^{\prime \prime} \mathrm{W}\right)$, both cities of São Paulo State, Brazil. In Araraquara, the sewage is subjected to aeration using full pond mixing, while in São José do Rio Preto a mixed treatment system is used (anaerobic followed by aeration with activated sludge).

All samples were dried at $100 \pm 5{ }^{\circ} \mathrm{C}$ for $24 \mathrm{~h}$, then grinded, and manually sieved (A Bronzinox sieves; São Paulo, Brazil). In order to address the contribution of the particle size to proximate analysis, sieves with different mesh sizes (Tyler) 500, 250, and $160 \mu \mathrm{m}$ were employed. Thus, after being dried and grinded, all samples were passed through the sieves arranged in sequence. Therefore, the average granulometry between 500 and $250 \mu \mathrm{m}$ was designated as ' $375 \mu \mathrm{m}$,' whereas the average granulometry between 250 and $160 \mu \mathrm{m}$ was designated as ' $205 \mu \mathrm{m}$.'

The elemental analysis was performed in the EA1110CHNS-O elemental analyzer (CE Instruments; Milan, Italy), and the high heating values (HHV) of samples was determined in the IKA C 2000 oxygen bomb calorimeter (IKA Works Inc.; Staufen, Germany).

\section{Thermogravimetric experiments}

All the experiments were carried out in the SDT 2960 Simultaneous TGA-DTA thermal analyzer (TA Instruments; New Castle, DE, USA), with the test materials placed in inert $\alpha$-alumina sample holder. Before the 
Table 1 Chemical properties of biomass samples

\begin{tabular}{|c|c|c|c|c|c|c|}
\hline \multirow[t]{2}{*}{ Biomass samples } & \multirow[t]{2}{*}{$\mathrm{HHV} / \mathrm{MJ} \mathrm{kg}^{-1}$} & \multicolumn{5}{|c|}{ Elemental analysis/mass \%, dry basis } \\
\hline & & $\mathrm{C}$ & $\mathrm{H}$ & $\mathrm{N}$ & S & $\mathrm{O}$ \\
\hline \multicolumn{7}{|l|}{ Sewage sludges } \\
\hline Mixed STP ${ }^{\mathrm{a}}$ & 13.94 & 31.73 & 6.34 & 4.37 & 0.78 & 27.51 \\
\hline Aerobic $\mathrm{STP}^{\mathrm{b}}$ & 12.12 & 28.12 & 4.08 & 3.29 & 0.90 & 17.30 \\
\hline Peanut shell & 16.52 & 41.52 & 7.43 & 2.11 & 0.60 & 27.74 \\
\hline Pine sawdust & 17.03 & 45.95 & 7.46 & 0.32 & 0.60 & 34.17 \\
\hline Coffee husk & 16.79 & 43.13 & 5.93 & 1.55 & 0.67 & 32.85 \\
\hline Rice husk & 15.39 & 31.46 & 6.67 & 1.04 & 0.51 & 22.91 \\
\hline Tисита̃ seed & 20.77 & 48.83 & 6.71 & 0.88 & - & 32.43 \\
\hline Sugar cane bagasse & 17.46 & 45.05 & 5.57 & 0.25 & - & 38.24 \\
\hline
\end{tabular}

${ }^{a}$ Sludge from mixed sewage treatment plant (anaerobic + aerobic)

${ }^{\mathrm{b}}$ Sludge from aerobic sewage treatment plant by full pond mixing

experiments, the equipment was calibrated for baseline, mass (with standard masses), and temperature (from the melting point of indium) in each experimental condition evaluated (heating rate, final temperature, and carrier gas).

A series of methods (M1, M2. M3, M4, M5, M5, M6, M7, and M8) consisting of different stepwise heating programs were designed to evaluate the influence of temperature, heating rate, and the furnace atmosphere on the release of volatiles. Table 2 presents the conditions established for each method.

The thermogravimetric programming considered two steps: (1) moisture and volatiles contents; (2) fixed carbon and ash contents. Step 1 was conducted under nitrogen $\left(\mathrm{N}_{2}\right)$ or carbon dioxide $\left(\mathrm{CO}_{2}\right)$ atmospheres, with gas flow rates of $130 \mathrm{~mL} \mathrm{~min}{ }^{-1}$. In each method, the same heating rate was maintained in both steps.

For moisture content determination, heating at $110^{\circ} \mathrm{C}$ was employed in all experiments. This temperature is an average of the values employed in several different standard methods E1131 [19], D7582 [11], E871 [5], and D3173 [20]. After reaching this temperature, the hold time (isothermal condition) adopted for the first experiments (30 $\mathrm{min}$ ) was reduced to $15 \mathrm{~min}$ for the subsequent experiments (M3-M8), since it was enough to ensure the mass stabilization before the next stage. For volatiles determination, the first experiments (M1 and M2) employed a final temperature of $950{ }^{\circ} \mathrm{C}$, based on standard method E872 [6].

Step 2 was performed after switching to an oxidizing atmosphere (compressed air, at a flow rate of $100 \mathrm{~mL} \mathrm{~min}^{-1}$ ). In this step, fixed carbon was determined from the mass loss caused by the chemical reaction between oxygen and fixed carbon.

According to the E1131 [19] standard method, the temperature of $750{ }^{\circ} \mathrm{C}$ was employed as the starting point for quantification of this component after volatiles release (M1, M2, and M3). However, lower temperatures such as
$700{ }^{\circ} \mathrm{C}(\mathrm{M} 4), 650{ }^{\circ} \mathrm{C}$ (M5), and $600{ }^{\circ} \mathrm{C}(\mathrm{M} 6, \mathrm{M} 7$, and M8) were subsequently evaluated in order to improve the separation of these components. The final residue represents the ash content of biomass sample.

The heating rate, particle size as well as type, and flow rate of the carrier gas were also evaluated. About heating rate, a comparison between $20{ }^{\circ} \mathrm{C} \mathrm{min}^{-1}$ (M6), $30{ }^{\circ} \mathrm{C} \min ^{-1}$ (M7), and $50{ }^{\circ} \mathrm{C} \min ^{-1}$ (M8) was made. The granulometry of particles in the samples tested, as previously mentioned, ranged from 106 to $500 \mu \mathrm{m}$. The carrier gasses employed were $\mathrm{CO}_{2}$ and $\mathrm{N}_{2}$, at flow rates between 30 and $130 \mathrm{~mL} \mathrm{~min}^{-1}$. The default sample mass used was $10 \mathrm{mg}$, which is recommended by E1131 [19] and provided a satisfactory mass distribution in the sample holder (close to half of its capacity), ensuring good thermal conductivity.

The main difference between M1 and M2 is that before fixed carbon evaluation, the release of volatiles content is performed up to $950{ }^{\circ} \mathrm{C}$, the first one under $\mathrm{N}_{2}$ and the second, under $\mathrm{CO}_{2}$. The M3, M4, M5, and M6 methods were performed to evaluate the influence of temperature: $750,700,650$, and $600{ }^{\circ} \mathrm{C}$, respectively. On the other hand, the effects of increasing the heating rate may be observed from M6 to M8. From M3, all methods were performed under $\mathrm{CO}_{2}$ atmosphere.

All the experimental conditions were assessed for each biomass type in search of plateau regions (with constant mass) in the thermogravimetric curves, which are essential to enable the distinction and quantification of each parameter in the continuous measurement.

\section{Validation of method}

To validate the thermal analytical method (M8), we calculated the confidence interval as well as the propagation of uncertainty of the data obtained from 10 replicates of pine sawdust and sewage sludge (from mixed STP). The 
Table 2 Summary of the thermogravimetric methods evaluated for the direct determination of all proximate analysis parameters of the biomass samples

\begin{tabular}{|c|c|c|c|c|c|c|c|}
\hline Methods & Properties & $\begin{array}{l}\text { Start } \\
\text { temperature } /{ }^{\circ} \mathrm{C}\end{array}$ & $\begin{array}{l}\text { Heating } \\
\text { rate } /{ }^{\circ} \mathrm{C} \min ^{-1}\end{array}$ & $\begin{array}{l}\text { Final } \\
\text { temperature } /{ }^{\circ} \mathrm{C}\end{array}$ & $\begin{array}{l}\text { Hold } \\
\text { time/min }\end{array}$ & Carrier gas & Elapsed time ${ }^{\mathrm{d}}$ \\
\hline \multirow[t]{6}{*}{ M1 } & Step 1 & & & & & & \\
\hline & Moisture & 30 & 20 & 110 & 30 & $\mathrm{~N}_{2}$ & $34 \mathrm{~min}$ \\
\hline & Volatiles & 110 & 20 & 950 & 7 & $\mathrm{~N}_{2}$ & $49 \min$ \\
\hline & Step 2 & & & & & & \\
\hline & Fixed carbon & 950 & $20^{\mathrm{b}}$ & $750^{\mathrm{c}}$ & 60 & Air & $70 \mathrm{~min}$ \\
\hline & $\mathrm{Ash}^{\mathrm{a}}$ & & & & & & $2 \mathrm{~h} 33 \min ^{\mathrm{e}}$ \\
\hline \multirow[t]{6}{*}{ M2 } & Step 1 & & & & & & \\
\hline & Moisture & 30 & 20 & 110 & 30 & $\mathrm{CO}_{2}$ & $34 \min$ \\
\hline & Volatiles & 110 & 20 & 950 & 7 & $\mathrm{CO}_{2}$ & $49 \min$ \\
\hline & Step 2 & & & & & & \\
\hline & Fixed carbon & 950 & $20^{\mathrm{b}}$ & $750^{\mathrm{c}}$ & 60 & Air & $70 \min$ \\
\hline & $\mathrm{Ash}^{\mathrm{a}}$ & & & & & & $2 \mathrm{~h} 33 \min ^{\mathrm{e}}$ \\
\hline \multirow[t]{6}{*}{ M3 } & Step 1 & & & & & & \\
\hline & Moisture & 30 & 20 & 110 & 15 & $\mathrm{CO}_{2}$ & $19 \min$ \\
\hline & Volatiles & 110 & 20 & 750 & 30 & $\mathrm{CO}_{2}$ & $62 \min$ \\
\hline & Step 2 & & & & & & \\
\hline & Fixed carbon & $750^{\mathrm{c}}$ & - & 750 & 30 & Air & $30 \min$ \\
\hline & $\mathrm{Ash}^{\mathrm{a}}$ & & & & & & $1 \mathrm{~h} 51 \mathrm{~min}^{\mathrm{e}}$ \\
\hline \multirow[t]{6}{*}{ M4 } & Step 1 & & & & & & \\
\hline & Moisture & 30 & 20 & 110 & 15 & $\mathrm{CO}_{2}$ & $19 \min$ \\
\hline & Volatiles & 110 & 20 & 700 & 30 & $\mathrm{CO}_{2}$ & $60 \mathrm{~min}$ \\
\hline & Step 2 & & & & & & \\
\hline & Fixed carbon & $700^{c}$ & - & 700 & 30 & Air & $30 \mathrm{~min}$ \\
\hline & $\mathrm{Ash}^{\mathrm{a}}$ & & & & & & $1 \mathrm{~h} 49 \min ^{\mathrm{e}}$ \\
\hline \multirow[t]{6}{*}{ M5 } & Step 1 & & & & & & \\
\hline & Moisture & 30 & 20 & 110 & 15 & $\mathrm{CO}_{2}$ & $19 \min$ \\
\hline & Volatiles & 110 & 20 & 650 & 30 & $\mathrm{CO}_{2}$ & $57 \mathrm{~min}$ \\
\hline & Step 2 & & & & & & \\
\hline & Fixed carbon & $650^{\mathrm{c}}$ & - & 650 & 30 & Air & $30 \mathrm{~min}$ \\
\hline & $\mathrm{Ash}^{\mathrm{a}}$ & & & & & & $1 \mathrm{~h} 46 \mathrm{~min}^{\mathrm{e}}$ \\
\hline \multirow[t]{6}{*}{ M6 } & Step 1 & & & & & & \\
\hline & Moisture & 30 & 20 & 110 & 15 & $\mathrm{CO}_{2}$ & $19 \min$ \\
\hline & Volatiles & 110 & 20 & 600 & 30 & $\mathrm{CO}_{2}$ & $55 \min$ \\
\hline & Step 2 & & & & & & \\
\hline & Fixed carbon & $600^{c}$ & - & 600 & 30 & Air & $30 \mathrm{~min}$ \\
\hline & $\mathrm{Ash}^{\mathrm{a}}$ & & & & & & $1 \mathrm{~h} 44 \min ^{\mathrm{e}}$ \\
\hline \multirow[t]{6}{*}{ M7 } & Step 1 & & & & & & \\
\hline & Moisture & 30 & 30 & 110 & 15 & $\mathrm{CO}_{2}$ & $18 \min$ \\
\hline & Volatiles & 110 & 30 & 600 & 30 & $\mathrm{CO}_{2}$ & $47 \min$ \\
\hline & Step 2 & & & & & & \\
\hline & Fixed carbon & $600^{c}$ & - & 600 & 30 & Air & $30 \mathrm{~min}$ \\
\hline & $\mathrm{Ash}^{\mathrm{a}}$ & & & & & & $1 \mathrm{~h} 35 \mathrm{~min}^{\mathrm{e}}$ \\
\hline \multirow[t]{3}{*}{ M8 } & Step 1 & & & & & & \\
\hline & Moisture & 30 & 50 & 110 & 15 & $\mathrm{CO}_{2}$ & $17 \mathrm{~min}$ \\
\hline & Volatiles & 110 & 50 & 600 & 30 & $\mathrm{CO}_{2}$ & $40 \mathrm{~min}$ \\
\hline
\end{tabular}


Table 2 continued

\begin{tabular}{|c|c|c|c|c|c|c|c|}
\hline Methods & Properties & $\begin{array}{l}\text { Start } \\
\text { temperature } /{ }^{\circ} \mathrm{C}\end{array}$ & $\begin{array}{l}\text { Heating } \\
\text { rate } /{ }^{\circ} \mathrm{C} \min ^{-1}\end{array}$ & $\begin{array}{l}\text { Final } \\
\text { temperature } /{ }^{\circ} \mathrm{C}\end{array}$ & $\begin{array}{l}\text { Hold } \\
\text { time/min }\end{array}$ & Carrier gas & Elapsed time $^{\mathrm{d}}$ \\
\hline & Step 2 & & & & & & \\
\hline & $\begin{array}{l}\text { Fixed carbon } \\
\text { Ash }^{\mathrm{a}}\end{array}$ & $600^{\mathrm{c}}$ & - & 600 & 30 & Air & $\begin{array}{l}30 \min \\
1 \mathrm{~h} 27 \mathrm{~min}^{\mathrm{e}}\end{array}$ \\
\hline
\end{tabular}

${ }^{\mathrm{a}}$ Ash content $=$ final residue, calculated by: $100 \%$ - [biomass total mass loss (\%)]

${ }^{\mathrm{b}}$ Cooling rate $\left({ }^{\circ} \mathrm{C} \mathrm{min}^{-1}\right)$. This procedure was only applied for M1 and M2

${ }^{c}$ Change point of furnace environment

d Time spent for determination of each parameter

e Total spent time for determination of all parameters, at the end of step 2

measures required for the method validation were performed using the average masses of $10.14 \pm 0.11$ and $10.15 \pm 0.12 \mathrm{mg}$, respectively.

The confidence interval was estimated for each parameter (moisture, volatiles, fixed carbon, and ash) by assuming a $95 \%$ confidence level (significance level of 0.05 ). For uncertainty estimation, we calculated the uncertainty contribution of each parameter as well as the combined standard uncertainty, when they were applied to predict the $\mathrm{HHV}$ of the related biomasses, by means of three different equations: Eqs. 1-3.

$$
\begin{aligned}
\operatorname{HHV}\left(\mathrm{MJ} \mathrm{kg}^{-1}\right)= & 0.3536(\mathrm{FC})+0.1559(\mathrm{VM}) \\
& -0.0078(\text { Ash }) \\
\operatorname{HHV}\left(\mathrm{MJ} \mathrm{kg}^{-1}\right)= & 19.2880-0.2135\left(\frac{\mathrm{VM}}{\mathrm{FC}}\right) \\
+ & 0.0234\left(\frac{\mathrm{FC}}{\mathrm{Ash}}\right)-1.9584\left(\frac{\mathrm{Ash}}{\mathrm{VM}}\right)
\end{aligned}
$$

$$
\begin{aligned}
\mathrm{HHV}\left(\mathrm{MJkg}^{-1}\right)= & 20.7999-0.3214\left(\frac{\mathrm{VM}}{\mathrm{FC}}\right) \\
& +0.0051\left(\frac{\mathrm{VM}}{\mathrm{FC}}\right)^{2}-11.2277\left(\frac{\mathrm{Ash}}{\mathrm{VM}}\right) \\
& +4.4953\left(\frac{\mathrm{Ash}}{\mathrm{VM}}\right)^{2}-0.7223\left(\frac{\mathrm{Ash}}{\mathrm{VM}}\right)^{3} \\
& +0.0383\left(\frac{\mathrm{Ash}}{\mathrm{VM}}\right)^{4}+0.0076\left(\frac{\mathrm{FC}}{\mathrm{Ash}}\right)
\end{aligned}
$$

where FC is fixed carbon and VM is volatile matter present in biomass.

The standard uncertainties (SU) resulting from the application of proximate analysis parameters (from M8) in the prediction of $\mathrm{HHV}$, according to Eqs. 1-3, are expressed in Eqs. 4-6, respectively. Note that in the case of nonlinear Eq. 3, either Eq. 5 or 6 might be used to calculate the standard uncertainty of its terms. All these calculations were performed according to EURACHEM Guide
[21], using the spreadsheet software Microsoft Excel ${ }^{\circledR}$, version 2013.

If $u=k x, \quad \Delta u_{\mathrm{x}}=k \Delta x$

where $u$ is a single term of Eq. $1, k$ is the constant value, $x$ is the proximate analysis parameter, $\Delta u_{\mathrm{x}}$ is the standard uncertainty of this term, and $\Delta x$ is the standard deviation of the parameter calculated by the mean of values (from the replicate of experiments).

If $u=x / y, \quad(\Delta u)^{2}=\left[1 / y^{2}(\Delta x)^{2}\right]+\left[x^{2} / y^{4}(\Delta y)^{2}\right]$

where $u$ is a single term of Eq. 2 or 3, $x$ and $y$ are the proximate analysis parameters, $\Delta x$ and $\Delta y$ are the respective standard deviations, and $\Delta u$ is the standard uncertainty of this term, expressed as a sum of relative standard deviations.

If $u=z^{\mathrm{n}}$, for $\mathrm{z}=x / y, \quad \Delta u=n(u / z)(\Delta z)$

where $u$ is a single term of Eq. 3, $z$ is the quotient of proximate analysis parameters, $n$ is the power in which $z$ is raised, $\Delta u$ is the standard uncertainty of the term $u$, and $\Delta z$ is the standard uncertainty of the quotient $z$, in which the calculation was demonstrated by Eq. 5 .

It is worth noting that after the calculation of the standard uncertainty according to Eqs. 5 and 6, it is necessary to multiply each term by its respective constant.

Given the above considerations, the combined standard uncertainty (CSU) of all components may be expressed as the positive square root of a sum of the squares of the individual uncertainty components.

\section{Results and discussion}

\section{Volatile and fixed carbon determination}

\section{Evaluation of the furnace atmosphere}

Figure 1 shows two thermogravimetric curves obtained using M1 and M2 methods for pine sawdust. For both 
methods, the thermal degradation occurs through two steps. The first, up to $80 \mathrm{~min}$ of analysis is related to mass loss of biomass under $\mathrm{N}_{2}$ (for M1) and $\mathrm{CO}_{2}$ (for M2) atmospheres. The second, from $80 \mathrm{~min}$ up to the end of the analysis corresponds to the thermal behavior of biomass under air atmosphere.

The moisture content was successfully determined under $\mathrm{N}_{2}$ atmosphere, with a plateau obtained after the mass loss at $110{ }^{\circ} \mathrm{C}$. Subsequently, with an increase in temperature and during the isothermal step, there was a continuous mass loss, even before switching to air atmosphere (up to $80 \mathrm{~min}$ ). This behavior resulted in a TG curve profile in which it was not possible to distinguish volatile matter and fixed carbon.

Under $\mathrm{N}_{2}$ atmosphere, the volatile matter content cannot be determined due to the pyrolysis process that occurs at higher temperatures $\left(<500{ }^{\circ} \mathrm{C}\right)$. The thermal decomposition of the main organic components of the biomass generates oxygenated by-products. As the temperature gradually increases, these by-products reach their spontaneous ignition, and the heat released contributes to the decomposition of the remaining organic matter. Such behavior is observed as a continuous mass loss due to the slight devolatilization [22] up to the end of the heating programming.

The devolatilization rate of the lignocellulosic biomass under nitrogen atmosphere depends on the amount of its components, with the cellulose responsible for the higher devolatilization rate in the early stage of pyrolysis and the higher lignin content, resulting in slower devolatilization with increasing temperature. This behavior was previously observed and reported by Gani and Naruse [23] in their study with wood chips.

The second method (M2) involves the replacement of nitrogen by $\mathrm{CO}_{2}$ and the maintenance of all the other

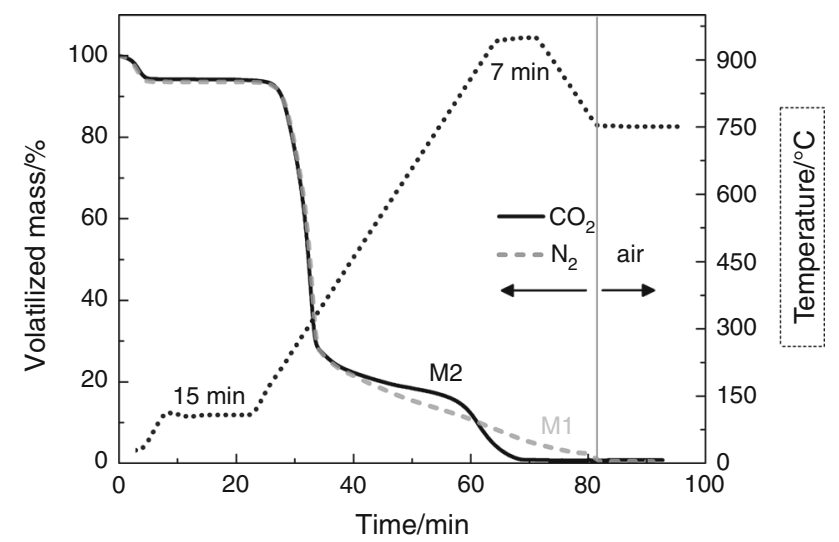

Fig. 1 Comparison between the thermogravimetric profiles for proximate analysis of pine sawdust $(205 \mu \mathrm{m}$ particle size) performed up to $950{ }^{\circ} \mathrm{C}$, using nitrogen and carbon dioxide atmospheres $\left(130 \mathrm{~mL} \mathrm{~min}^{-1}\right)$ experimental conditions. The moisture content was successfully determined, but this method was unsatisfactory for the determination of volatile materials.

According to Fig. 1, an event of mass loss occurs prior to switching from $\mathrm{CO}_{2}$ to air. This behavior can be explained by the gasification reaction that takes place after devolatilization. As illustrated in Fig. 2, at lower temperatures $\left(<700{ }^{\circ} \mathrm{C}\right)$ less stable compounds are released, and char is formed by means of the devolatilization process (reaction 1). In contact with $\mathrm{CO}_{2}$ at higher temperatures $\left(>700{ }^{\circ} \mathrm{C}\right)$, and given sufficient residence time, the char can undergo a Boudouard reaction, which leads to $\mathrm{CO}$ formation (reaction 2) [24-26].

Biomass $\rightarrow$ char + gases

$\mathrm{C}_{(\text {char })}+\mathrm{CO}_{2(\mathrm{~g})} \rightarrow 2 \mathrm{CO}_{(\mathrm{g})}$

The mechanism proposed for the gasification reaction [27-29] comprises two stages: (i) the adsorption of $\mathrm{CO}_{2}$ in the active sites of biomass char $\left(\mathrm{C}^{\circ}\right)$, leading to the formation of a carbon-oxygen complex $(* \mathrm{C}(\mathrm{O}))$, and (ii) $\mathrm{CO}$ release by the rearrangement of $* \mathrm{C}(\mathrm{O})$. The oxygen exchange phenomenon is expressed according to reaction 3. The carbon transfer from the solid phase to the gas phase (unidirectional reaction) is represented by reaction 4 .

$\mathrm{CO}_{(\text {char })}+\mathrm{CO}_{2(\mathrm{~g})} \leftrightharpoons{ }^{*} \mathrm{C}(\mathrm{O})_{(\text {char })}+\mathrm{CO}_{(\mathrm{g})}$

${ }^{*} \mathrm{C}(\mathrm{O})_{(\text {char })} \rightarrow \mathrm{CO}_{(\mathrm{g})}+\mathrm{nCO}_{(\text {char })}$

According to Ergun [30], the reduction of carbon dioxide to carbon monoxide on a carbon surface (reaction 3) occurs at temperatures as low as $600{ }^{\circ} \mathrm{C}$. On the other hand, $\mathrm{CO}$ is also generated from the biomass devolatilization [29].

When the concentration of $\mathrm{CO}$ is higher than that of the thermodynamic equilibrium between $\mathrm{CO}$ and $\mathrm{CO}_{2}$, the

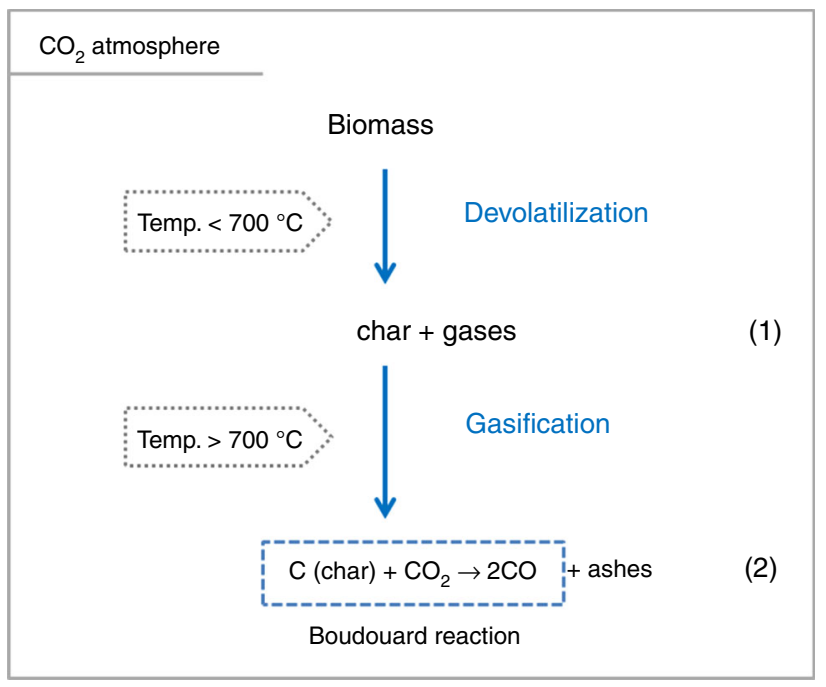

Fig. 2 Devolatilization and gasification of biomasses in $\mathrm{CO}_{2}$ atmosphere 
equilibrium of reaction 3 is shifted to the reagent side, resulting in a free site and consequently preventing the occurrence of reaction 4. Hence, at lower temperatures CO becomes an inhibitor of char gasification [30].

Furthermore, char gasification is thermodynamically susceptible at temperatures above $720{ }^{\circ} \mathrm{C}$ [31], reaching higher yields between 800 and $950{ }^{\circ} \mathrm{C}$ [32].

Therefore, the use of temperatures of up to $950{ }^{\circ} \mathrm{C}$ is not appropriate for the quantification of volatile and fixed carbon contents, in either $\mathrm{N}_{2}$ or $\mathrm{CO}_{2}$ atmospheres. The effect of temperature on the determinations was therefore evaluated using lower temperatures $(600,650,700$, and $\left.750{ }^{\circ} \mathrm{C}\right)$.

\section{Evaluation of temperature}

The main objective of reducing the temperature was to achieve a mass loss plateau in the TG curves after the release of the volatile matter to ensure its separation from the fixed carbon content.

A series of four methods (M3, M4, M5, and M6) were designed with temperatures of $750,700,650$, and $600{ }^{\circ} \mathrm{C}$, respectively, as described in Table 2 . The thermogravimetric curves obtained for each method are shown in Fig. 3. Pine sawdust was the sample chosen to illustrate the TG profile for lignocellulosic biomass.

The temperature was found to have a significant effect on the volatile matter determination, because as the final temperature was decreased, there was a trend toward reaching a plateau in the TG curves up to the end of isotherm period in step (1), i.e., before the atmosphere had been switched from $\mathrm{CO}_{2}$ to air.

As shown in Fig. $3 \mathrm{a}$, when $750{ }^{\circ} \mathrm{C}$ was applied as the final temperature of step (1), there was no evidence of reaching a plateau in the TG curve. Such behavior indicates that the fixed carbon present in the sample is decomposed together with the volatiles. Therefore, under $750{ }^{\circ} \mathrm{C}$, it was not possible to distinguish or quantify these biomass fractions.

On the other hand, when $600{ }^{\circ} \mathrm{C}$ was applied as the final temperature of step (1), a trend toward reaching a mass loss plateau can be observed after the complete devolatilization and the volatile matter can be quantified. The related TG curve profile enables the assessment of the fixed carbon content after the carrier gas has been switched to air and the complete combustion has occurred.

To ensure that the best choice of the final temperature would be $600{ }^{\circ} \mathrm{C}$, another type of biomass was evaluated, the sewage sludge. The TG curves of this residue are shown in Fig. 3b. The increase in the final temperature (from 600 to $750{ }^{\circ} \mathrm{C}$ ) had an even greater effect on the release of volatile compounds in complex biomasses, such
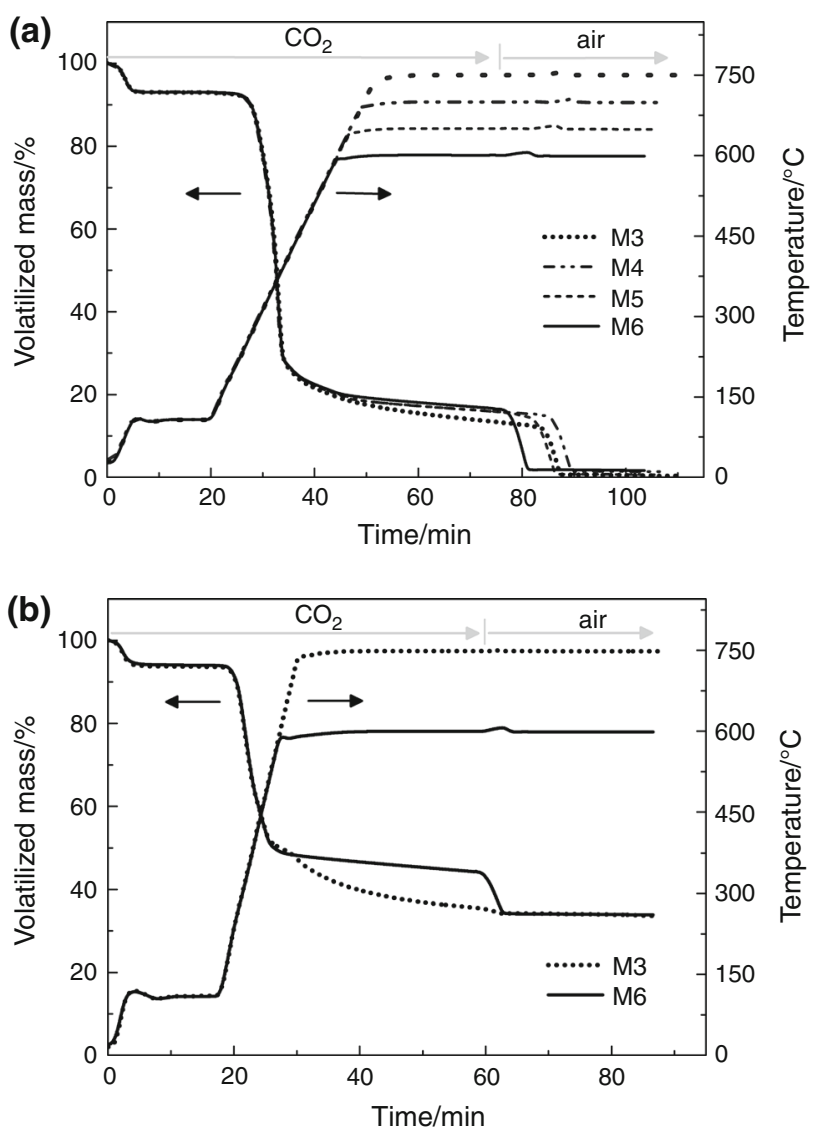

Fig. 3 Thermogravimetric curves for: a pine sawdust sample applying M3, M4, M5, and M6 methods, b sewage sludge sample applying M3 and M6 methods. Evaluation of the effect of temperature increase on determination of volatile matter and fixed carbon

as sewage sludge. This change in temperature provided TG profiles with the same value of ash content. Thereby, as the total mass loss of biomasses did not change, the differences observed in their TG curves might be due to the increase in the rate of organic matter decomposition and not due to the heterogeneity of the samples.

Most studies have shown that both lignocellulosic and waste biomass materials have their major devolatilization zone (around $95 \%$ of total mass loss) at temperatures of up to $600{ }^{\circ} \mathrm{C}[10,22,25]$.

Moreover, clay minerals and carbonates present in large amounts in biomasses such as sludge and municipal solid waste decompose at temperatures around $750{ }^{\circ} \mathrm{C}$ [33]. Thereby, the application of such high temperatures for the quantification of volatile organic contents in this type of biomass may also lead to inappropriate results in proximate analysis. The temperature of $600{ }^{\circ} \mathrm{C}$ is, therefore, the most suitable to quantify and distinguish volatile and fixed carbon in biomass samples.

After the assessment of the most suitable furnace atmosphere and temperature for the proximate analysis, 
other experimental conditions were evaluated to improve the proposed methodology.

\section{Evaluation of the influence of other experimental conditions}

\section{Biomass particle size}

TG curves of different particles sizes $(<106,205,375$, and $>500 \mu \mathrm{m}$ ) obtained by the M6 method for lignocellulosic material and sewage sludge are shown in Fig. 4. The TG curve profiles for both samples and all particle sizes were similar with respect to devolatilization and char combustion. However, the behavior of particle sizes $<106 \mu \mathrm{m}$ was different from the others. In this case, there was a lower mass loss in devolatilization and a corresponding increase in the ash content.

These results were unexpected since both volatile matter and ash contents are characteristics of the samples and should not depend on the particle size. However, they are in agreement with those reported by Bridgeman et al. [34], who evaluated different fractions of crops and observed that the inorganic constituents are segregated from the lignocellulosic components during the milling and further sieving. This process favors the selection and the accumulation of inorganic components, which have smaller particles, resulting in higher ash and relative lower volatile matter contents.

This behavior was even more pronounced for sewage sludge, i.e., the TG curves obtained for smaller particles (Fig. 4b) showed approximately $10 \%$ less mass loss during the devolatilization, compared to the larger particles, because this residue contains large amount of inorganic compounds coming from the wastewater and retained during the treatment in UWWTP.

Therefore, the particle size is an important parameter that must be taken into account for the application of the thermogravimetric method. The results showed that particles of $205 \mu \mathrm{m}$ or larger should preferably be used in these analyses.

\section{Heating rate}

The TG curves of the pine sawdust and sewage sludge samples $(205 \mu \mathrm{m}$ particle size $)$ obtained from room temperature to $600{ }^{\circ} \mathrm{C}$ at different heating rates $20{ }^{\circ} \mathrm{C} \mathrm{min}{ }^{-1}$ (M6), $30{ }^{\circ} \mathrm{C} \min ^{-1}$ (M7), and $50{ }^{\circ} \mathrm{C} \mathrm{min}{ }^{-1}$ (M8) are shown in the supplementary data (Fig. S1). It is clear that for both biomasses, the increase in the heating rate causes a more pronounced devolatilization, although this did not affect the attainment of constant mass under isothermal condition.
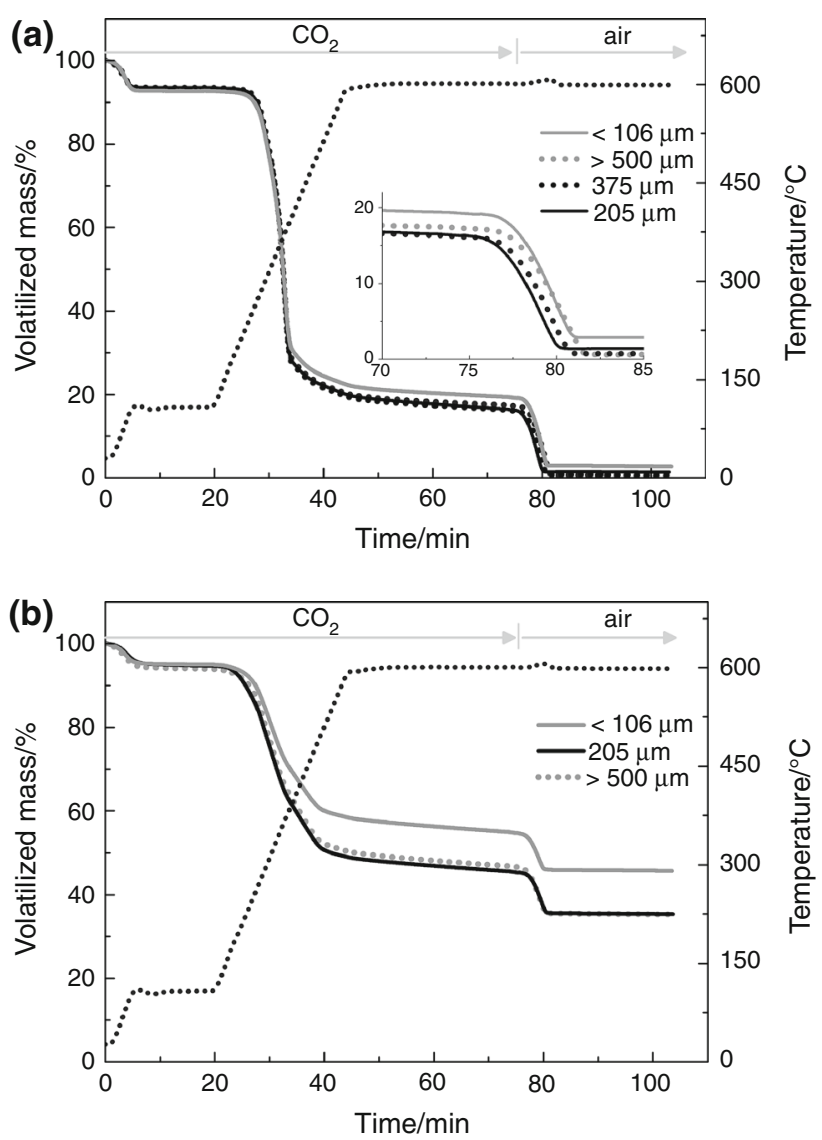

Fig. 4 Thermogravimetric curves obtained by M6 method using different particle sizes $(<106,205,375$ and $>500 \mu \mathrm{m})$ of: a pine sawdust, b sewage sludge

According to Lai et al. [25], for a very complex biomasses, such as MSW (municipal solid wastes), the increase in heating rate shortens the devolatilization time and may increase the residual mass under $\mathrm{CO}_{2}$ atmosphere. However, in the present case, the results obtained for both lignocellulosic and sewage sludge samples showed no increase in residual mass (ash content) when the heating rate changed from 20 to $50{ }^{\circ} \mathrm{C} \mathrm{min}{ }^{-1}$.

These results indicate that the high heating rate of $50{ }^{\circ} \mathrm{C} \min ^{-1}$ (M8) may be used, without affecting the quantification of biomass properties, besides allowing the time saving during proximate analysis.

\section{Type and flow of the carrier gas}

Figure 5 shows the TG curves obtained using $\mathrm{CO}_{2}$ as a carrier gas under three different flow rates (70, 100, and $130 \mathrm{~mL} \mathrm{~min}^{-1}$ ) for pine sawdust. The flow rate of $130 \mathrm{~mL} \mathrm{~min}^{-1}$ was selected because it enables the stabilization of the mass and the volatile matter can be therefore completely released before the stage of fixed carbon evaluation. 


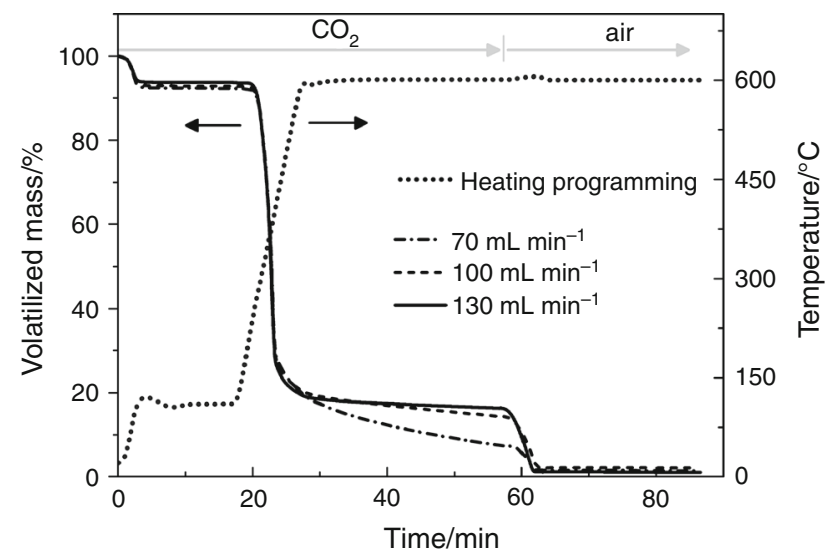

Fig. 5 Thermogravimetric profiles for proximate analysis of pine sawdust, applying M8 method with different flows of carbon dioxide: 70,100 , and $130 \mathrm{~mL} \mathrm{~min}^{-1}$

Figure 6 shows the TG curves for two different lignocellulosic biomass samples pine sawdust and peanut shell (Fig. 6a, b, respectively), and sludge (Fig. 6c) under both $\mathrm{N}_{2}$ and $\mathrm{CO}_{2}$ atmospheres, employing flow rates of $130 \mathrm{~mL} \mathrm{~min}{ }^{-1}$. The results evidence that when $\mathrm{N}_{2}$ is used, it was not possible to identify the devolatilization endpoint after the isothermal period. On the other hand, the use of $\mathrm{CO}_{2}$ greatly improved the achievement of a mass loss plateau during the isothermal step, enabling the discrimination and quantification of the contents of volatile material and fixed carbon in the biomass samples.

According to Borrego and Alvarez [35], the use of $\mathrm{CO}_{2}$ as a carrier gas provided higher resistance to the devolatilization of bulk components of wood chips about $\mathrm{N}_{2}$. It may be due to the involvement of $\mathrm{CO}_{2}$ in the 'crosslinking' reaction on the surface of the char, which reduces the deformation and clumping of the carbonaceous structure. However, morphological characteristics, as well as the reactivity of char surface, are similar under both atmospheres $[24,36]$.

After the evaluation of several parameters for the methodology optimization, it was clear that $\mathrm{CO}_{2}$, instead of $\mathrm{N}_{2}$, is more suitable for reaching a mass loss plateau after biomass devolatilization.

\section{Summary of findings and application to samples}

Figure 7 provides an overview of the TG curve obtained using the optimized conditions for proximate analysis of the pine sawdust biomass, using the experimental conditions described for M8 method (Table 2). The important point is that this methodology enables the quantification of moisture, volatile matter, fixed carbon, and ash in a significantly short time (1 h $27 \mathrm{~min})$, compared to the standard methods.
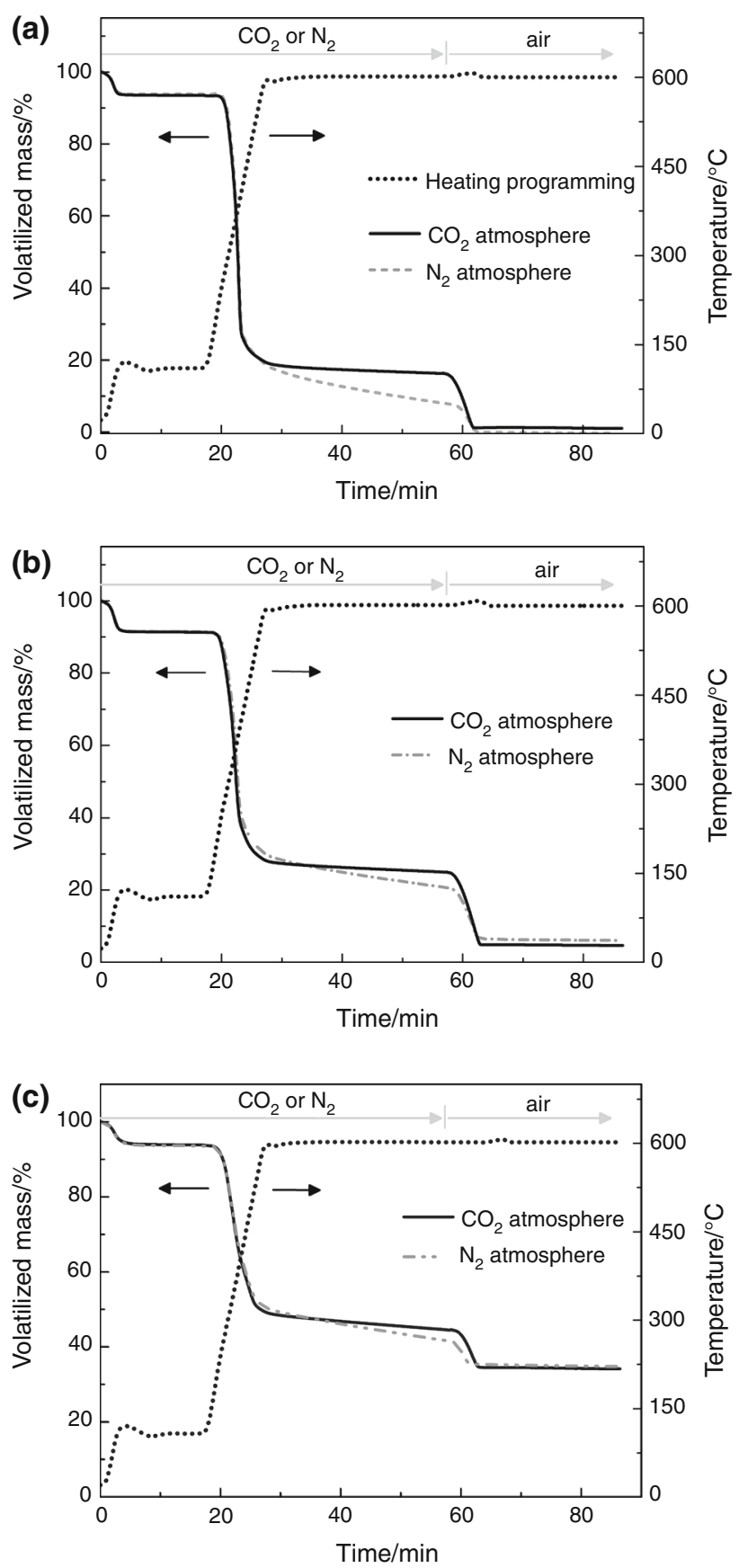

Fig. 6 Comparison between the thermogravimetric profiles of a pine sawdust, b peanut shell, and c sewage sludge samples, using M8 method under carbon dioxide and nitrogen, both in the flow of $130 \mathrm{~mL} \mathrm{~min}^{-1}$

This methodology was applied in the proximate analysis of different biomasses (lignocellulosic materials, sewage sludges, and blends), providing thermogravimetric profiles specific for each sample type (Fig. 8a, b respectively), which clearly demonstrate the compositional differences between them. The data obtained from theses TG curves are displayed in Table 3. It is worth emphasizing that all 


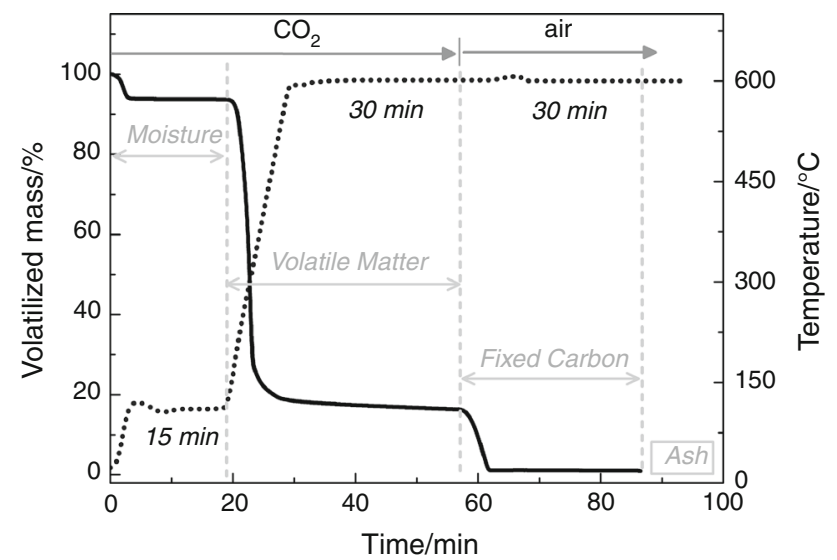

Fig. 7 General profile of the thermogravimetric method (M8) developed for proximate analysis of biomasses

the measurements were made in triplicate to ensure accuracy and reproducibility.

\section{Validation of method (M8)}

Due to the high compositional variability of biomass, it is hard to establish a database of parameters that include moisture content, fixed carbon, volatile matter, and ash, as well as elemental composition and heating rates, among others.

Possible ways of validating the proposal method (M8) include the use of reference materials or the comparison of results with those obtained using standard methods. However, certified reference materials for proximate analysis are not available for every type or species of biomass.

Concerning standard methods for proximate analysis, all procedures employ temperatures up to $900{ }^{\circ} \mathrm{C}$, or above, for the determination of volatile matter and fixed carbon. As previously mentioned, such high temperatures could promote the complete decomposition of organic compounds, making it difficult to distinguish between the volatile matter and fixed carbon present in the biomass.

To elucidate the applicability of the data obtained by the proposed methodology, they were applied to predict the high heating values (HHV) of biomasses by different empirical equations: Eq. (1) [37], Eqs. (2), and (3) [38]. The results were compared with the corresponding experimental data, obtained in a bomb calorimeter, as well as with those obtained from ultimate analysis data (shown in Table 1), using Eq. (7) [39]. These correlations were applied to all biomass samples and are summarized in Table 4, where $\mathrm{HHV}_{\mathrm{c}}$ and $\mathrm{HHV}_{\mathrm{m}}$ are defined as calculated and measured values of $\mathrm{HHV}$, respectively.

$\operatorname{HHV}\left(\mathrm{MJ} \mathrm{kg}^{-1}\right)=[33.5(\% \mathrm{C})+142.3(\% \mathrm{H})-15.4(\% \mathrm{O})] / 100$
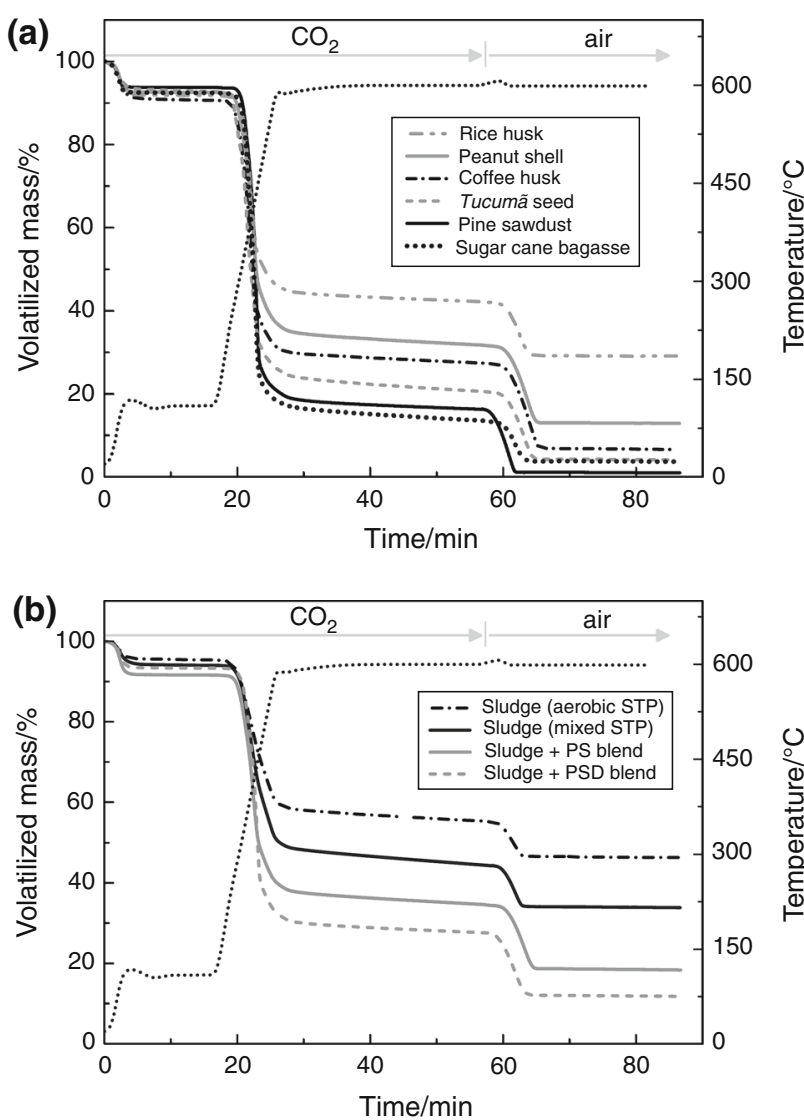

Fig. 8 Proximate analysis of biomass samples performed using M8. a Lignocellulosic samples; b sludge samples and blends

where $\mathrm{C}, \mathrm{H}$, and $\mathrm{O}$ are the content of carbon, hydrogen, and oxygen, respectively.

The differences between the $\mathrm{HHV}_{\mathrm{m}}$ and the $\mathrm{HHV}_{\mathrm{c}}$ values can be seen more clearly using the absolute error, also expressed in $\mathrm{MJ} \mathrm{kg}^{-1}$ (Eq. 8), supplied for each equation applied in this table.

Absolute error $(\mathrm{AE})=\left|\mathrm{HHV}_{\mathrm{c}}-\mathrm{HHV}_{\mathrm{m}}\right|$

According to the absolute errors, the $\mathrm{HHV}_{\mathrm{c}}$ values obtained from the data of proximate analysis are in good agreement with the related $\mathrm{HHV}_{\mathrm{m}}$, especially in the case of sugar cane bagasse (by Eq. 2), peanut shell, pine sawdust, and coffee husk (by Eq. 1). In the case of peanut shell and pine sawdust, the absolute errors obtained by proximate analysis were even lower than obtained for comparison with the elemental analysis. Therefore, the data obtained by M8 provided a good prediction of HHV, which depends on the equation selected.

Furthermore, to validate this method we use the same equations for proximate analysis (Eqs. 1-3) but only for pine sawdust and sewage sludge, since they demonstrated opposite behaviors on proximate analysis: the first one with high volatile matter and lower ash content and the second, 
Table 3 Properties of proximate analysis obtained for different types of biomass and blends, using the proposed method (M8)

\begin{tabular}{|c|c|c|c|c|}
\hline \multirow[t]{2}{*}{ Biomass samples } & \multicolumn{4}{|c|}{ Proximate analysis/\% } \\
\hline & Moisture & $\begin{array}{l}\text { Volatile } \\
\text { matter }\end{array}$ & $\begin{array}{l}\text { Fixed } \\
\text { carbon }\end{array}$ & Ash \\
\hline \multicolumn{5}{|l|}{ Sewage sludges } \\
\hline Mixed STP & 5.25 & 49.67 & 9.42 & 35.66 \\
\hline Aerobic STP & 4.70 & 40.20 & 8.90 & 46.30 \\
\hline Peanut shell (PS) & 7.43 & 60.51 & 18.90 & 13.17 \\
\hline Pine sawdust (PSD) & 6.42 & 77.68 & 14.95 & 0.93 \\
\hline Sludge $^{\mathrm{a}}+$ PS blend & 8.43 & 57.02 & 16.03 & 18.51 \\
\hline Sludge $^{\mathrm{b}}+$ PSD blend & 6.74 & 65.33 & 16.10 & 11.83 \\
\hline Coffee husk & 9.44 & 63.15 & 20.99 & 6.43 \\
\hline Rice husk & 8.14 & 49.74 & 12.85 & 29.27 \\
\hline Tисита̃ seed & 7.27 & 72.31 & 16.54 & 3.88 \\
\hline Sugar cane bagasse & 7.39 & 79.30 & 9.81 & 3.50 \\
\hline
\end{tabular}

with low volatile matter and high ash content. Thus, it would be possible to observe the propagation of uncertainty for very different biomasses, covering the compositional range between them.

The confidence interval for all data obtained from proximate analysis of pine sawdust and sewage sludge (M8) is shown in Table 5. The values of each property measured by this methodology are in the range specified with $95 \%$ of confidence.

The width of the confidence interval is the difference between the upper and the lower limit of the confidence interval and expresses the uncertainty in measurement. In other words, the width of a confidence interval is a parameter that characterizes the dispersion of the values that could be attributed to the value measured [21].

The higher width of the confidence interval observed for pine sawdust was in ashes, while to sewage sludge, the higher width was found in volatiles. For pine sample, it can be attributed to its very low amount of ashes, sometimes close to the equipment uncertainty. About the sludge, this behavior of volatiles is acceptable, given its complex and heterogeneous organic composition.

With the purpose of demonstrating the effect of this variance in the prediction of HHV, we calculated the HHV for Eqs. 1-3, supposing two situations: one of them with all parameters in the lower limit and the other with an upper limit of the confidence interval. The oscillation of values of HHV in this interval can be observed in Table 5.

In Table 6 are presented the proximate analysis parameters (or quotient of parameters) with lower and higher contribution to the uncertainty calculation as well as the combined standard uncertainty in the evaluation of HHV using Eqs. 1-3.

About pine sawdust, the higher source of uncertainty was the quotient (FC/Ash) in Eq. 2, which reflects in its higher combined standard uncertainty of 0.46 . Concerning the sludge, the higher contribution to uncertainty estimation was obtained from the term $(\mathrm{VM} / \mathrm{FC})^{2}$, responsible for the higher combined standard uncertainty of 0.22 for HHV calculation by Eq. 3 .

In general, either pine sawdust or sewage sludge demonstrated low propagation of uncertainty in the prediction of HHV for all evaluated equations.

The results demonstrated that the data of proximate analysis obtained with the proposed methodology provided a good prediction of HHV. In other words, these correlations support the applicability of the data achieved in the present study by the experimental conditions adopted and for the range of biomass explored.

Table 4 Comparison between $\mathrm{HHV}_{\mathrm{m}}$ and $\mathrm{HHV}_{\mathrm{c}}$ values obtained from proximate and ultimate analysis of biomass samples

\begin{tabular}{|c|c|c|c|c|c|c|c|c|c|}
\hline \multirow[t]{3}{*}{ Biomass samples } & \multirow[t]{3}{*}{$\mathrm{HHV}_{\mathrm{m}} / \mathrm{MJ} \mathrm{kg}^{-1}$} & \multicolumn{8}{|c|}{$\mathrm{HHV}_{\mathrm{c}} / \mathrm{MJ} \mathrm{kg}^{-1}$} \\
\hline & & \multicolumn{6}{|c|}{ Proximate analysis } & \multicolumn{2}{|c|}{ Ultimate analysis } \\
\hline & & Equation (1) & $\mathrm{AE}^{\mathrm{a}}$ & Equation (2) & $\mathrm{AE}$ & Equation (3) & $\mathrm{AE}$ & Equation (7) & $\mathrm{AE}$ \\
\hline \multicolumn{10}{|l|}{ Sewage sludge } \\
\hline Mixed STP & 13.94 & 10.79 & 3.15 & 16.76 & 2.82 & 13.25 & 0.69 & 15.35 & 1.41 \\
\hline Aerobic STP & 12.12 & 9.05 & 3.07 & 16.07 & 3.95 & 11.45 & 0.67 & 12.57 & 0.45 \\
\hline Peanut shell & 16.52 & 16.00 & 0.52 & 18.21 & 1.69 & 17.59 & 1.07 & 20.17 & 3.65 \\
\hline Pine sawdust & 17.03 & 17.38 & 0.35 & 18.53 & 1.50 & 19.25 & 2.22 & 20.83 & 3.80 \\
\hline Coffee husk & 16.79 & 17.20 & 0.41 & 18.52 & 1.73 & 18.81 & 2.02 & 17.92 & 1.13 \\
\hline Rice husk & 15.39 & 12.06 & 3.33 & 17.32 & 1.23 & 14.44 & 0.95 & 16.54 & 1.15 \\
\hline Tисита̃ seed & 20.77 & 17.08 & 3.69 & 18.35 & 2.42 & 18.93 & 1.83 & 20.95 & 0.19 \\
\hline Sugar cane bagasse & 17.46 & 15.79 & 1.66 & 17.54 & 0.08 & 18.07 & 0.61 & 17.16 & 0.30 \\
\hline
\end{tabular}

\footnotetext{
${ }^{a}$ Absolute error
} 


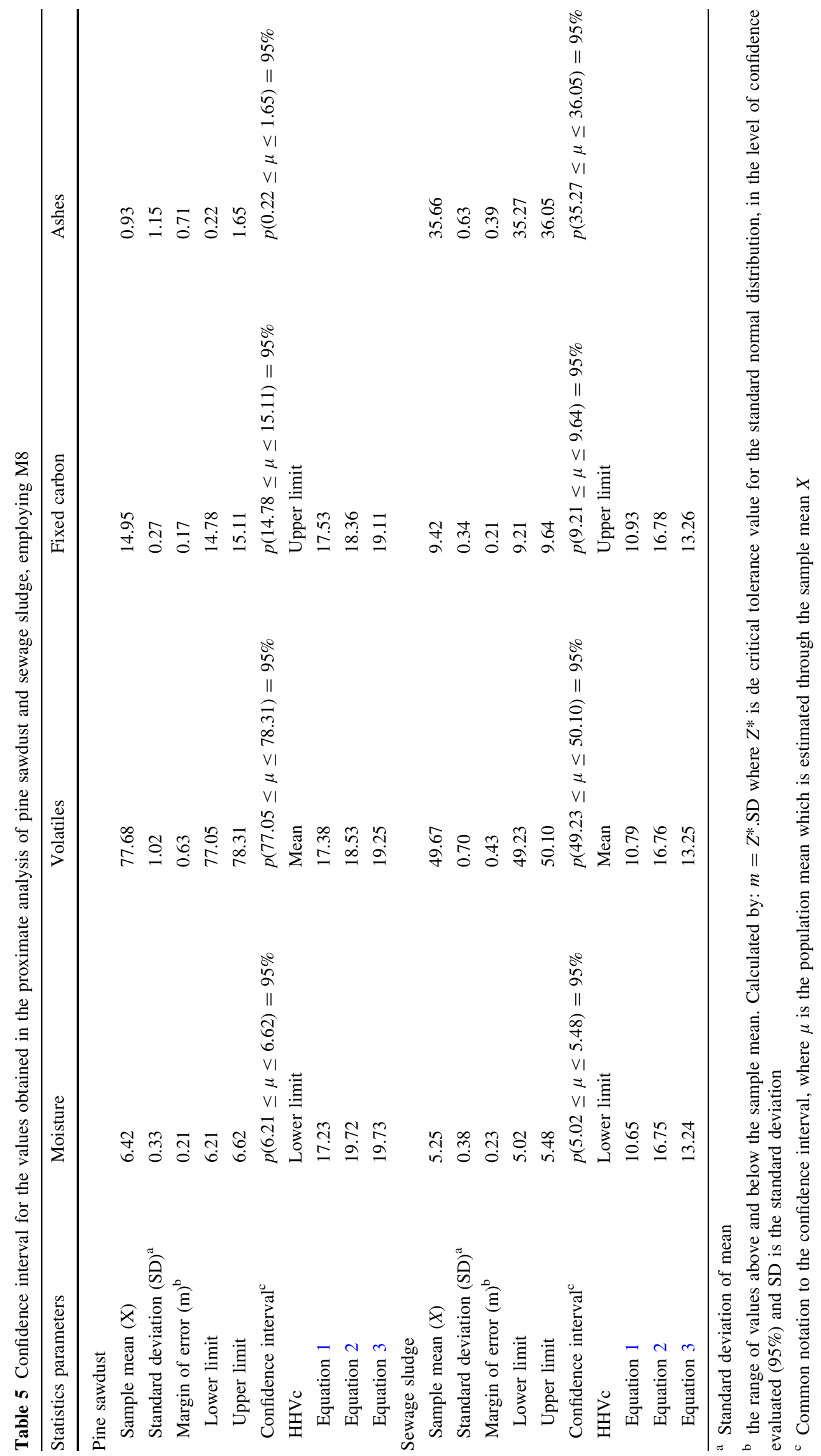


Table 6 Propagation of uncertainty for estimation of HHV by Eqs. 1-3, using the parameters obtained in M8 for pine sawdust and sewage sludge

\begin{tabular}{|c|c|c|c|c|}
\hline & \multicolumn{4}{|c|}{ Propagation of uncertainty } \\
\hline & \multicolumn{2}{|l|}{ Pine sawdust } & \multicolumn{2}{|c|}{ Sewage sludge } \\
\hline & Parameters & $\mathrm{RSD}^{\mathrm{a}}$ & Parameters & RSD \\
\hline \multicolumn{5}{|c|}{ Equation 1} \\
\hline $\mathrm{LC}^{\mathrm{b}}$ & Ash & $9.0 \mathrm{E}-3$ & Ash & $5.0 \mathrm{E}-3$ \\
\hline \multirow[t]{2}{*}{$\mathrm{HC}^{\mathrm{c}}$} & VM & 0.16 & $\mathrm{FC}$ & 0.12 \\
\hline & $\mathrm{CSU}^{\mathrm{d}}$ & 0.18 & CSU & 0.16 \\
\hline \multicolumn{5}{|c|}{ Equation 2} \\
\hline LC & (Ash/VM) & $1.5 \mathrm{E}-2$ & (FC/Ash) & $1.0 \mathrm{E}-2$ \\
\hline \multirow[t]{2}{*}{$\mathrm{HC}$} & (FC/Ash) & 19.64 & (VM/FC) & 0.20 \\
\hline & $\mathrm{CSU}$ & 0.46 & $\mathrm{CSU}$ & $5.0 \mathrm{E}-2$ \\
\hline \multicolumn{5}{|c|}{ Equation 3} \\
\hline LC & (Ash/VM) & $1.0 \mathrm{E}-7$ & (FC/Ash) & 0.10 \\
\hline \multirow[t]{2}{*}{$\mathrm{HC}$} & (VM/FC) & 1.20 & (VM/FC) & 2.17 \\
\hline & CSU & 0.22 & CSU & 0.22 \\
\hline
\end{tabular}

\section{Conclusions}

Thermogravimetry was used for the direct measurement of all proximate analysis parameters in a single measure. According to the set of experimental conditions evaluated in this work, the importance of controlling mainly temperature and carrier gas for the proper performance of biomass proximate analysis by thermogravimetry became clear. The methodology proposed (M8) enables the direct and fast measurement of all proximate analysis properties in biomass, providing a thermogravimetric profile that is unique for each sample.

The greatest contribution of this methodology to biomass characterization is the improvement on distinction and quantification of volatile and fixed carbon contents. Such conditions were obtained by employing carbon dioxide, instead of nitrogen, as a carrier gas and the temperature of $600{ }^{\circ} \mathrm{C}$ for volatiles release, which are substantially different from the conditions often applied for this purpose.

Furthermore, the proposed methodology has provided accurate results (low uncertainty), when applied to predict the high heating value of either lignocellulosic or a complex biomass as sewage sludge. Therefore, it can be used as an alternative thermogravimetric method for characterization of biomass, which is essential when proposing its use as feedstock for power generation.
Acknowledgements The authors would like to acknowledge FAPESP (Process n. 2012/00639-9) for the financial support provided by this research, and CAPES for a scholarship awarded to L. D. M. Torquato. Technical assistance from Carlos E. M. Braz is acknowledged. The authors are indebted to Angela Pregnolato Giampedro for the English language review.

\section{References}

1. Demirbas A. Combustion characteristics of different biomass fuels. Prog Energy Combust Sci. 2004;30(2):219-30.

2. McKendry P. Energy production from biomass (part 1): overview of biomass. Bioresour Technol. 2002;83(1):37-46.

3. Chiang KY, Chien KL, Lu CH. Characterization and comparison of biomass produced from various sources: suggestions for selection of pretreatment technologies in biomass-to-energy. Appl Energy. 2012;100:164-71.

4. Ebeling JM, Jenkins BM. Physical and chemical properties of biomass fuels. Trans ASAE. 1985;28(3):898-902.

5. ASTM. Standard test method for moisture analysis of particulate wood fuels E871-82, vol. 2006. ASTM, West Conshohocken, PA (USA): American Society for Testing and Materials; 2013.

6. ASTM. Standard test method for volatile matter in the analysis of particulate wood fuels E872-82, vol. 2006. ASTM, West Conshohocken, PA (USA): American Society for Testing and Materials; 2013.

7. ASTM. Standard test method for ash in wood D1102-84, vol. 2007. ASTM, West Conshohocken, PA (USA): American Society for Testing and Materials; 2013.

8. Basu P. Chapter 2-biomass characteristics. In: Basu P, editor. Biomass gasification and pyrolysis: practical design and theory. Boston: Academic Press; 2010. p. 27-63.

9. ASTM. Standard test method for volatile matter in the analysis sample of coal and coke D3175-11, vol. 2007. ASTM, West Conshohocken, PA (USA): American Society for Testing and Materials; 2011.

10. Biagini E, Lippi F, Petarca L, Tognotti L. Devolatilization rate of biomasses and coal-biomass blends: an experimental investigation. Fuel. 2002;81(8):1041-50.

11. ASTM. Standard test method for proximate analysis of coal and coke by macro thermogravimetric analysis D7582-12, vol. 2010. ASTM, West Conshohocken, PA (USA): American Society for Testing and Materials; 2012.

12. Karatepe N, Küçükbayrak S. Proximate analysis of some Turkish lignites by thermogravimetry. Thermochim Acta. 1993;213:147-50.

13. Mayoral MC, Izquierdo MT, Andrés JM, Rubio B. Different approaches to proximate analysis by thermogravimetry analysis. Thermochim Acta. 2001;370(1-2):91-7.

14. Ottaway M. Use of thermogravimetry for proximate analysis of coals and cokes. Fuel. 1982;61(8):713-6.

15. Sadek FS, Herrell AY. Methods of proximate analysis by thermogravimetry. Thermochim Acta. 1984;81:297-303.

16. Warne SSJ. Proximate analysis of coal, oil shale, low quality fossil fuels and related materials by thermogravimetry. Trends Anal Chem. 1991;10(6):195-9.

17. Cantrell KB, Martin JH, Ro KS. Application of thermogravimetric analysis for the proximate analysis of livestock wastes. J ASTM Int. 2010;7(3):JAI102583.

18. García R, Pizarro C, Lavín AG, Bueno JL. Biomass proximate analysis using thermogravimetry. Bioresour Technol. 2013;139:1-4.

19. ASTM. Standard test method for compositional analysis by thermogravimetry E1131-08, vol. 2008. ASTM, West Conshohocken, PA (USA): American Society for Testing and Materials; 2014. 
20. ASTM. Standard test method for moisture in the analysis sample of coal and coke D3173-11, vol. 2008. ASTM, West Conshohocken, PA (USA): American Society for Testing and Materials; 2011.

21. Ellison SLR, Williams A (editors). Eurachem/CITAC guide: Quantifying Uncertainty in Analytical Measurement, 3rd ed., (2012) ISBN 978-0-948926-30-3. Available from www.eur achem.org.

22. Munir S, Daood SS, Nimmo W, Cunliffe AM, Gibbs BM. Thermal analysis and devolatilization kinetics of cotton stalk, sugar cane bagasse and shea meal under nitrogen and air atmospheres. Bioresour Technol. 2009;100(3):1413-8.

23. Gani A, Naruse I. Effect of cellulose and lignin content on pyrolysis and combustion characteristics for several types of biomass. Renew Energy. 2007;32(4):649-61.

24. Gil MV, Riaza J, Álvarez L, Pevida C, Pis JJ, Rubiera F. Kinetic models for the oxy-fuel combustion of coal and coal/biomass blend chars obtained in $\mathrm{N}_{2}$ and $\mathrm{CO}_{2}$ atmospheres. Energy. 2012;48(1):510-8.

25. Lai $Z$, Ma X, Tang $Y$, Lin $H$. Thermogravimetric analysis of the thermal decomposition of MSW in $\mathrm{N}_{2}, \mathrm{CO}_{2}$, and $\mathrm{CO}_{2} / \mathrm{N}_{2}$ atmospheres. Fuel Process Technol. 2012;102:18-23.

26. Moon J, Lee J, Lee U, Hwang J. Transient behavior of devolatilization and char reaction during steam gasification of biomass. Bioresour Technol. 2013;133:429-36.

27. Di Blasi C. Combustion and gasification rates of lignocellulosic chars. Prog Energy Combust Sci. 2009;35(2):121-40.

28. Scott SA, Davidson JF, Dennis JS, Fennell PS, Hayhurst AN. The rate of gasification by $\mathrm{CO}_{2}$ of chars from waste. Proc Combust Inst. 2005;30(2):2151-9.

29. Shen D, Hu J, Xiao R, Zhang H, Li S, Gu S. Online evolved gas analysis by thermogravimetric-mass spectroscopy for thermal decomposition of biomass and its components under different atmospheres: part I. Lignin Bioresour Technol. 2013;130:449-56.
30. Ergun S. Kinetics of the reaction of carbon with carbon dioxide. J Phys Chem. 1956;60(4):480-5.

31. Kwon EE, Jeon YJ, Yi H. New candidate for biofuel feedstock beyond terrestrial biomass for thermo-chemical process (pyrolysis/gasification) enhanced by carbon dioxide $\left(\mathrm{CO}_{2}\right)$. Bioresour Technol. 2012;123:673-7.

32. Vamvuka D, Karouki E, Sfakiotakis S. Gasification of waste biomass chars by carbon dioxide via thermogravimetry. Part I: effect of mineral matter. Fuel. 2011;90(3):1120-7.

33. Campana A, Martins Q, Crespi M, Ribeiro C, Barud H. Thermal behavior of residues (sludge) originated from Araraquara water and sewage treatment station. $\mathrm{J}$ Therm Anal Calorim. 2009;97(2):601-4.

34. Bridgeman TG, Darvell LI, Jones JM, Williams PT, Fahmi R, Bridgwater AV, et al. Influence of particle size on the analytical and chemical properties of two energy crops. Fuel. 2007;86(1-2):60-72.

35. Borrego AG, Alvarez D. Comparison of chars obtained under oxy-fuel and conventional pulverized coal combustion atmospheres. Energy Fuels. 2007;21(6):3171-9.

36. Borrego AG, Garavaglia L, Kalkreuth WD. Characteristics of high heating rate biomass chars prepared under $\mathrm{N}_{2}$ and $\mathrm{CO}_{2}$ atmospheres. Int J Coal Geol. 2009;77(3-4):409-15.

37. Parikh J, Channiwala S, Ghosal G. A correlation for calculating HHV from proximate analysis of solid fuels. Fuel. 2005;84(5):487-94.

38. Nhuchhen DR, Abdul Salam P. Estimation of higher heating value of biomass from proximate analysis: a new approach. Fuel. 2012;99:55-63.

39. Nanda S, Mohanty P, Pant KK, Naik S, Kozinski JA, Dalai AK. Characterization of North American lignocellulosic biomass and biochars in terms of their candidacy for alternate renewable fuels. Bioenergy Res. 2012;6(2):663-77. 